\title{
Expectations on Swedish Rescue Archaeology: fertile circles, the courage not to know, and texts with meaning
}

\author{
Elisabeth Rudebeck
}

\begin{abstract}
This paper discusses some general problems within Swedish rescue archaeology. In order to illustrate these problems, more or less recognizable negative states are contrasted with positive expectations. Vicious circles, prohibiting critical evaluation and discussion, are contrasted with "fertile circles", promoting an intellectual and creative archaeology. The comfortable and stagnant search for "known" and easily categorized features and objects is contrasted with the courage to actively focus on problematic features and relations. Finally, archaeological reports that are anxiously occupied with numbers and descriptive "facts", while avoiding subjective reflexions and interpretations, are contrasted with reports communicating meaning, interpretations and evaluations.
\end{abstract}

Elisabeth Rudebeck, Institute of Archaeology, University of Lund, Sandgatan 1, S-223 50 Lund, Sweden.

\section{INTRODUCTION}

Like many (?) Swedish archaeologists, I find myself today with one foot in the trench and the other on the desk - to use the more vulgar metaphors for rescue archaeology and academical archaeology. Although this position is somewhat uncomfortable, it also offers the possibility of viewing the two spheres, and oneself, from different perspectives. Through my experiences of the two archaeological worlds my views continually change, and it has become increasingly difficult to make sweeping generalizations about "the other" world and its presumed qualities. It is also difficult to know to what extent such generalizations represent anything more than one's own local and personal experiences.

In this article I would like to discuss a few problems concerning visions of knowledge within Swedish rescue archaeology.
The discussion inevitably builds on my subjective perspective and particular way of generalizing about this archaeological world. In spite of this, I am convinced that several archaeologists will recognize the problems, although there may be different views on how to deal with them.

\section{EXPECTATIONS ON SWEDISH RESCUE ARCHAEOLOGY}

Most archaeologists who have lived within the world of rescue archaeology for some time have probably had one or more positive expectations thoroughly crushed. In several cases these disappointing experiences have probably had to do with the lack of visions of knowledge within this world.

There are several possible ways to enter a discussion on this subject. In order to limit this contribution I have chosen to focus on a few selected themes. First, however, I would like to clearify my views on certain 
aspects of rescue archaeology and to discuss some concepts that are often encountered when this archaeology is discussed.

I prefer the term meaning to the term knowledge. Knowledge is, as I see it, usually associated with the idea that some predetermined amount of information is at hand at each archaeological investigation or within each feature. Knowledge thus becomes something given, a measurable quantity from which one may have extracted more or less. In my view, archaeological investigations, like all other kinds of archaeological research, are not performed in order to extract a certain degree or percentage of a given amount of knowledge supposedly inherent in archaeological remains. Instead, this research is about viewing and investigating archaeological remains from certain perspectives or with certain questions in mind. If we take as a starting point perspectives and questions rather than a presumed inherent amount of information, we may render meaning to archaeological remains. This also implies an awareness that remains cannot be investigated from all possible perspectives; i.e., that we choose certain perspectives at the cost of others.

Furthermore it is not possible to determine perspectives and questions entirely beforehand; i.e., before the investigation. Every archaeological investigation implies a large amount of unpredictability. Therefore, flexibility and continual evaluation is demanded in order to make active and conscious choices of perspectives, questions and methods. Archaeological investigations are primarily an intellectual and creative activity, and as with all such activities it is not possible to predetermine exactly what actions are to be chosen or how they are to be executed in the best way. The search for meaning - or knowledge, if you like - is not a linear process between predictable steps or points.

It is the choice of perspective that ought to be the foundation for the choice of methods and priorities. Within rescue archaeology, however, we often encounter the opinion that methods are given, decided from convention and from the limitations of funding. This is unfortunate in that the limits to what perspectives may be chosen are largely decided from factors that do not take the search for meaning as a starting point.

I want to emphasize here that I do not equal perspectives with priorities. The latter word is often used in connection with rescue archaeology and it has, to my opinion, been used rhetorically in the critique against - and also in the discussion within - rescue archaeology. Rescue archaeologists are often considered to be incapable of performing priorities on scientific grounds. Although this may partly be true, when considered as an incapacity to choose perspectives and ask questions, the rhetorical use of the term priorities often concerns the efforts among private and public entrepreneurs to lower costs for archaeological investigations. The term is used in this context to convince rescue archaeologists to "let go" of certain remains, from economical rather than from archaeological considerations.

It may seem irrelevant to some to focus here on particular concepts and words within the archaeological world. To this I would like to answer that "there is much implicit in a word". Certain concepts are connected to certain practices, and if we find it necessary to criticize and discuss certain practices within rescue archaeology, the terms legitimizing these practices ought to be scrutinized. We think in terms of concepts and if we are interested in trying to think differently and change practices, we also must try to find new concepts to think through.

In the following, I would like to discuss three connected themes through which I will formulate expectations on Swedish rescue archaeology. Within each theme I will contrast negative states, more or less recognizable and realistic, with my positive expectations. The three themes concern:

- vicious circles as opposed to fertile circles

- investigating what you understand as 
opposed to investigating what you do not understand - the courage not to know - writing - accounting for quantitative data as opposed to texts with meaning

\section{VICIOUS CIRCLES AS OPPOSED TO FERTILE CIRCLES}

The world of the vicious circles is characterized by a kind of compulsive repetition (to borrow a term from psychology). You repeat what you did before, without having evaluated the positive and negative effects of your previous thinking and previous actions. In this world there is a creed that a higher force once and for all has decided how the Law on the Protection of Ancient Monuments (Sw. Kulturminneslagen) is to be interpreted and applied and how the practice of archaeology is to be conducted. In this world no one feels responsible for how this law is applied in practice. In this world archaeologists are "creatures of the soil" and their true home is the field and its dark spots. In this world it is most important to believe that one has found the ultimate method for handling different quantitative "bulks" and their temporal and spatial transportation, whether it be hours, square meters, cubic meters, personnel, equipment, money or tons of flint.

In this world thinking and writing are potential disturbances in the machinery, or tasks that may be performed when the important transportation of "bulks" is interrupted by bad weather or economic recession. In this world thinking and talking about the "whats, whys and hows" of archaeology is regarded as unnecessary repetition and as a sign of uncertainty. In the world of the vicious circles one always knows what to do and how to do it; i.e., "as before", but preferably faster and cheaper. In this world critical evaluation of assembled results (i.e. reports and publications) is not important because - in case they would in fact be produced - they would not be used for anything anyway, except for being sent to antiquarian authorities and put in files that no one will ever care about.

To conclude: the world of the vicious circles is in fact a world of only one circle,

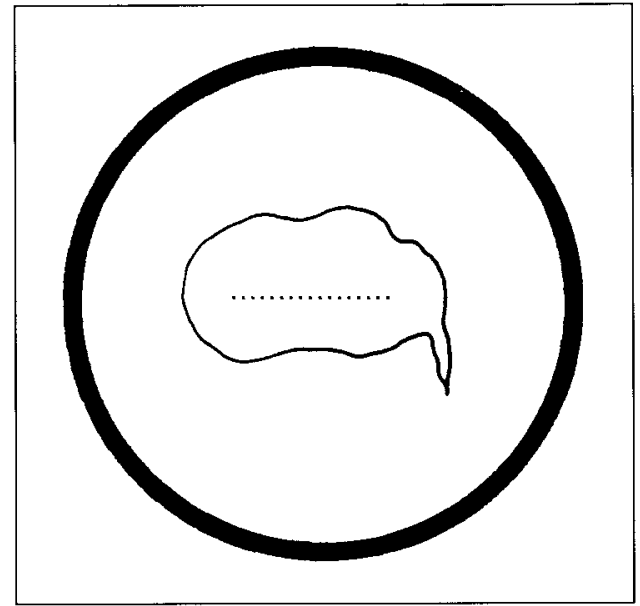

Fig. Ia. The vicious circle.

entirely closed in itself. It is held together by silence and it always looks the same. This world is a lid shutting in and closing out (fig 1a).

The world of the fertile circles is different. In this world the aim is to avoid compulsive repetition. There is a will to understand what one is doing and to evaluate the positive and negative implications of one's previous actions. In this world one wants to discuss how to proceed the next time. Evaluation and critical discussion is demanded in this world, both of particular investigations and of the application of the Law on the Protection of Ancient Monuments. In this world there is an awareness of individual interests and capacities and there is a will to make use of these in practice. In this world one feels responsible for how archaeology is conducted in the country.

In the world of the fertile circles the fact that archaeologists are educated on rescue excavations is taken seriously, and one therefore understands that this education requires time and resources. In this world archaeology is an intellectual and creative activity demanding argument and responsibility. One is curious, in this world, as to the possibilities of archaeology to render meaning to material remains in terms of human life. In this good world it is not un- 


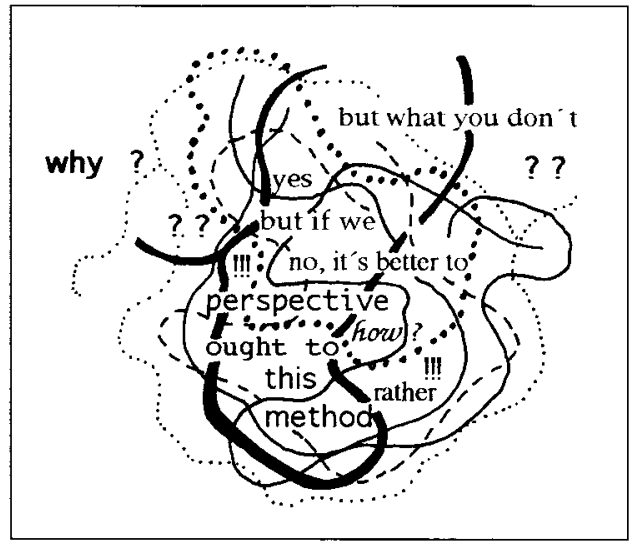

Fig. 1b. The fertile circle.

til one has told in writing about what was investigated and why and how, that the archaeological investigation exists.

To conclude: the world of the fertile circles is constituted by several lines, lines that change shape and direction, lines that cross and affect each other. The circles in this world are held together by a continual discussion, they change over time and they are open to the world (fig 1b).

\section{INVESTIGATING WHAT YOU UNDERSTAND AS OPPOSED TO INVESTIGATING WHAT YOU DO NOT UNDERSTAND}

\section{- THE COURAGE NOT TO KNOW}

When you only want to investigate what you already understand you want to find patterns that you have found before. You feel happy and secure in what you recognize and you do not even understand that you neglect that which you do not recognize. Investigations are concentrated on recognizable and already defined remains. You prefer remains to be obviously intentional and synchronous and you always look for "Pompeii". The house and the grave are always regarded as more worthy of investigation than are the unclear and unnamed layers and traces in between. You focus on objects rather than on relations and you want to produce clearly defined and unambiguosly categorized features, because only these features can legitimize your investigation. You do not want to see the unknown and the unclear - the features with no names. You do not have any questions concerning what you do not understand you do not have courage not to know (fig 2a).

When, instead, you want to investigate what you do not understand, you actively look for problematic features that are difficult to recognize. Your investigation focuses on what you do not understand and why you do not understand it. The intentional and easily identified and named feature is not automatically regarded as more worthy of your efforts than is the unintentional and complex feature. You focus on spatial and temporal relations rather than on objects. You understand that several different processes continuosly are at work in archaeological remains and that, in a sense, "Pompeii" does not exist at all, because panta rei - "everything flows". You prefer to ask what it is you do not understand rather than answering what you know - you have the courage not to know (fig $2 b$ ).

\section{WRITING - ACCOUNTING FOR QUANTITATIVE DATA AS OPPOSED TO TEXTS WITH MEANING}

When you prefer to account for quantitative data, the written presentation of an archaeological investigation and its results is unproblematic and it mainly consists of measures, numbers and administrative information. The archaeological report here becomes an excercise in numbers and a question, not of writing, but of counting. The author of the report is to be hidden as much as possible behind presumed objective statements. Subjective reflexions are banned as they are, precisely, subjective. What is to be presented here is "facts". A good report is here the finished report, irrespective of its content and quality. In this world it is not considered a problem that archaeologists often have very little writing experience and/or feel a lack of confidence when it comes to expressing their thoughts and actions in writing. The writing of archaeological reports is not seen as an 


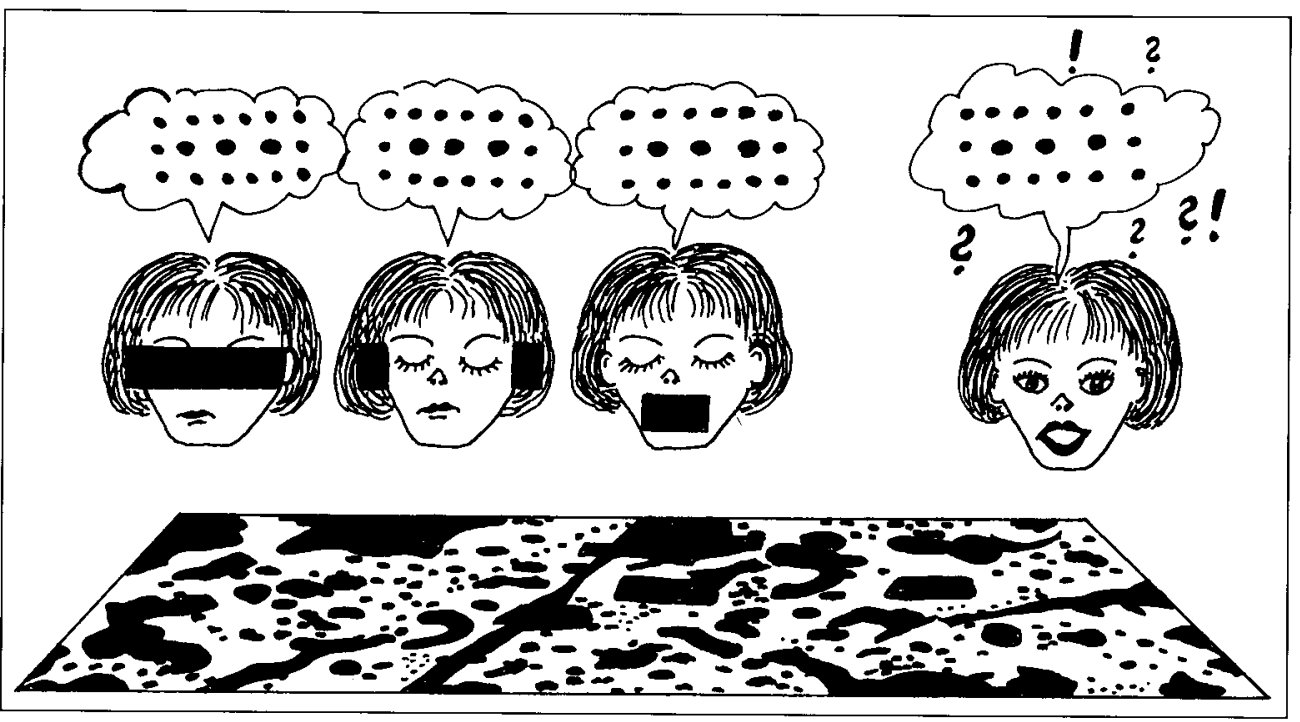

Fig. 2a. Investigating what you understand.

Fig. 2b. The courage not to know.

activity demanding any kind of "advanced" writing or verbal expression anyway. To educate and stimulate archaeologists to improve their writing capacity is not seen as an important task. To do so would be to admit a weakness in the system, and that of course would be destructive to the selfconfidence and, above all, it would not look good in the eyes of others (fig 3a).

The opposite to this is trying to write texts with meaning, trying to communicate something essential to your colleagues. This

11 black stones $0.5-1.35 \mathrm{~m}$ high, $0.6-2.8 \mathrm{~m}$ broad and $0.2-0.3 \mathrm{~m}$ thick. The north western gable stone is $0.8 \mathrm{~m}$ high, $1.3 \mathrm{~m}$ broad and $0.2-0.3 \mathrm{~m}$ thick. $5 \mathrm{~m}$ south east of the north eastern gable stone there is another stone $1 \mathrm{~m}$ high, $2.6 \mathrm{~m}$ broad and $0.5 \mathrm{~m}$ thick. South east of the cairn there is a

Fig. 3a. Accounting for quantitative data. is seen as a most problematic and important task. Subjective reflections concerning the investigation and its results are considered to be of source critical value, and regarded as a sign of responsibility and interest in archaeology. A good report is not entirely engaged in number exercise, but rather a presentation and a discussion with the aid of words, concepts, figures and drawings. The aim of the report is to put forward selected themes or perspectives on the investigated remains and to present

cannot be understood only from a functionalistic point of view. A dwelling house is intentionally designed, following a set of traditional rules of construction, to a large degree dictated by extrafunctional specifications. The actual occurrence of two types of pit dwellings during the

Fig. 3b. Texts with meaning. 
interpretations and evaluations. This, of course, also implies that relevant observations and documentations are presented.

Here it is considered a problem that archaeologists often lack the self-confidence and the capacity to express themselves in writing. It is also admitted that this problem concerns the whole hierarchy of the archaeological world, from the bottom to the top. The awareness of this problem is however not experienced as a threat. Therefore there is a will to take actions for improving the capacity to write. Education within these matters is encouraged and initiated and resources at hand are activated in order to improve the state of affairs. Archaeological reports and other writings are seen as voices in a never ending debate concerning our preconceptions and concerning what perspectives on prehistory and on the present - that we should focus on in our research and how this may be accomplished (fig 3b).

Because ultimately archaeology is about how we view the relation between the human being, society, culture and nature - in the present and in the past - and what images of these relations we work with, interpret through and reproduce in the present.

\section{ACKNOWLEDGEMENTS}

Thanks to Björn Varenius for comments on the script and to Debbie Olausson for revising the English. 